\title{
Influence Of Strategic Planning On Performance Of State Corporations In Kenya
}

\author{
"John Muturi Mwangi PhD, ** Morris Irungu Kariuki PhD \& ${ }^{* * * *}$ Peter Githae Muturi PhD. \\ *Manager, National Authority for the Campaign Against Alcohol and Drug Abuse (NACADA), Nairobi, Kenya \\ ${ }^{* * *}$ Lecturer, University of Nairobi, Nairobi, Kenya \\ *** Jomo Kenyatta University of Agriculture and Technology, Nairobi, Kenya \\ DOI: 10.29322/IJSRP.10.05.2020.p10153 \\ http://dx.doi.org/10.29322/IJSRP.10.05.2020.p10153
}

\begin{abstract}
Despite the fact that State Corporations have been established internationally to support Governments efforts, their performance continue to be a major concern in most countries. Research has shown that strategic planning is one of the tools that organizations can employ to enhance their performance. The need to link strategic planning with performance has become crucial for organizations seeking superior performance. However, there has been no rich literature linking the two. To better understand this relationship, this study was underpinned on resource based view theory and was guided by cross sectional research design. The theoretical models and hypothesis in the study were tested based on data gathered from 102 respondents that were randomly selected from a population of 200 State Corporations in Kenya. The results of correlation indicated that for any improvement in strategic plan, there was a corresponding improvement in the performance composite score and vice versa. Regression analysis results revealed that the predictor variable explained $20 \%$ of the variance in dependent variable. From these findings, the study recommended that State Corporations should develop strategic plans and implement them to realize better performance.
\end{abstract}

Index Terms- Corporate performance, State Corporations, Strategic Planning, Strategic Plan Implementation.

\section{INTRODUCTION}

$\mathrm{T}$ 1.1 Background

o support social economic development globally, Fourie (2014) pointed out that most Governments have established State Corporations which are also known as State Owned Enterprises (SOEs). In Africa, the SOEs were mainly started in the 1960s after most countries attained their independence while in some isolated cases such like Ghana, State Corporations were established before independence and have continued to increase rapidly. Michael (2002) noted that the number of State Corporations in Tanzania increased from 42 in 1967 to 425 in 1984 while Simpson (2013) stated that in Ghana, State Corporations rose from 4 in 1957 to 53 in 1960. Despite the growth in number, majority of the State Corporations have performed poorly in many countries including South Africa (Kanyane \& Sausi, 2015) and Tanzania (Michael, 2002). This impelled restructuring of these corporations. For example, in Ghana, the economic recovery programme was started in 1983 to facilitate divestiture of the State Corporations.
In Kenya, the appearance of State Corporations has undergone the same process as in other African countries. The history of SOEs can be traced back to independence. Some of the corporations that were established in the early 1960s include Agricultural Development Corporation (ADC), Industrial Development Bank (IDB), Housing Finance Company of Kenya (HFCK) and Agricultural Finance Corporation (AFC). Several policy guidelines and laws have been enacted by the Government to facilitate establishment and proper functioning of these corporations. The Sessional Paper Number 10 was published in 1965 to speed up state involvement in public investment (RoK, 1965). On $1^{\text {st }}$ November 1986 the State Corporation Act Cap 446 of was enacted to guide the establishment and functioning of State Corporations in the country (RoK, 2012).

Additionally, the Government of Kenya introduced performance contracting in 2004 to improve performance of State Corporations. This is a negotiated contract between the Government and the management of State Corporations (Ochieng, 2010). The contract spells out the obligations of both parties and milestones. Njiru (2008) highlighted the main challenges affecting State Corporations in Kenya as; insufficient financial resources, prolonged procurement process, maintenance of infrastructure, HIV/AIDS and poor institutional frame work. Other problems that have been pointed out include lack of clarity on the role of State Corporations, fast change in global infrastructure, weak linkage of State Corporations and national goals, deprived policy coordination, weak governance, poor governance boards, bloated boards, political interference, inconsistent remuneration, weakly trained human resource and poor performance (RoK, 2013).

\subsection{Statement of the Problem}

Performance of Kenyan State Corporations remain pertinent for both micro and macro-economic development in the country. This sector has the ability to contribute more positively to the Kenyan economy than is currently the case. But to survive in a rapidly changing business environment strategic planning is necessary. Therefore, it is hoped that by through strategic planning, the performance of state corporations in Kenya may be enhanced. However, literature on the relationship between strategic planning and performance of state corporations in Kenya is limited. Thus, the relationship remains blurred. This is the rationale for conducting this study.

\subsection{Specific Objectives}


To establish the influence of strategic planning on performance of State Corporations in Kenya.

\subsection{Hypothesis}

There is no significant influence of strategic planning on performance of State Corporations in Kenya.

\section{LITERATURE REVIEW}

\subsection{Resource based view theory (RBV)}

This theory states that a firms performance is influenced by resources available (Madhani, 2010). The theory was postulated in the 1980s with much of the debate about it being held in the 1990s. Wade and Hulland (2004) defined resources as assets and capabilities that enable a firm to capture the market while Priem and Butler (2001) argued that while availability of these resources is necessary, improvement in a firms' performance cannot be realized without using the resources effectively and efficiently. Newbert (2007) has argued that it is not the static resources that form the basis of competitive advantage. Rather it is the organization capabilities, valuable, non-imitable and substitutable resources that make the difference. For these resources to promote sustainable competitive advantage, they need to satisfy the value, rarity, imitability and non-substitutability (VRIN) criteria (Barney, 1991). This will ensure protection and insulation from competitors (Brown, 2007). Gaya and Struwig (2016) opined that understanding firms' competitive advantage would be possible if the RBV was merged with the activity based view (ABV) to form activity and resource based view (ARBV). Kabue and Kilika (2016) pointed out that since resources in most cases are common, firms can only achieve competitive advantage through adoption of core competencies such as organization culture and values. A key strength of this theory is provision of a frame work for sustainable competitive advantage and recognition of organization internal resources (Jurevicius, 2013).

Critics have however argued that the theory is tautological (Priem \& Butler 2001). This is because it highlights the importance of resource to be valuable. It has been argued that a resource that is not valuable is useless and hence not a resource. Other criticisms are that the theory pays no attention to the product market and it is difficult to find a resource that meets the VRIN criteria. Further, the rarity concept is obsolete since a resource that is valuable, non-imitable and non-substitutable is already rare (Hoopes, Malses \& Walker, 2003). This theory is relevant to this study because it viewed strategic planning as one resource which is essential in corporate performance. It is a resource that enhances capabilities of a firm. However having a strategic plan may not influence corporate performance if this is not implemented effectively.

\subsection{Strategic planning}

Strategic plan gives an organization direction towards achieving its mission and vision. Rouse (2013) opined that through strategic planning process, executives make thoughtful decision regarding the organization mission, vision and values as well as resource allocation to achieve these goals. The strategic plan visualizes what the organization would like to achieve in the future (Poister, 2010). Usually, the future may be defined as a period of five years or less. During this period the document can be revised to capture current trends and events. It is the future goals that inform the vision, mission, values, goals and objectives to be pursued. Objectives are quantifiable, measurable and time bound business needs (Frantz, 2013). From the objectives, the specific activities are formulated.

This process considers both the macro and micro environment (Kaissi, Bengun \& Hamiliton, 2008). The macro environment constitutes the factors that influence the organization externally. These are also referred to as the PESTEL factors and include political, economic, social, technological, environmental and legal factors (Jurevicious, 2013). Micro environment refers to organizational strength, weakness opportunities and threats. Some scholars have stated that a strategic plan needs to be implemented to attain the full benefits of this process (Poister, 2010). When the plan is not implemented, it is as good as no plan. Kaissi et al (2008) have used four indicators in measurement of strategic planning. These are a comprehensive strategic plan, involvement of physicians and involvement of the board as well as the implementation of the plan. Song, Im, Bij and Song (2011) have used three measures for strategic planning namely existence of a strategic plan, implementation and monitoring of the plan. This study defined strategic planning as encompassing both the development of the strategic plan as well as its implementation in line with previous studies.

\subsection{Performance of State Corporations}

Public institutions have been under increasing scrutiny to demonstrate impact as well as increased efficiency and effectiveness globally (André, 2010). While global consensus on performance measurement for public institutions is evident, the process of measurement has encountered some challenges. A concern has been that the indices used in performance measurement for public institutions are heavily borrowed from the private sector. Walker (2008) has stated that the use of private sector based indices does not reflect the public sector environment. This position is reinforced by Anjula (2009) who has argued that, public sector is different from private sector and has unique distinctive capabilities that are absent from the private sector. Berg, Grift and Witteloostuijn (2011) while studying Dutch organizations measured performance using the economic position of a firm. Gestel, Voets and Verhoest (2012) have used two parameters in measurement of performance in public private partnerships. These are product performance which is the process of conversion of inputs into outputs. The second parameter is process performance measured in terms of cooperation, partnership and trust. Theil and Leeuw (2002) have argued that performance assessment often leads to un-intended consequences. Such may include lack of innovation as managers' focus on parameters that would ultimately be measured. Further, Karen, Jiju and Susan (2009), argued that performance measurement has not improved transparency, accountability and service delivery in some countries like United Kingdom. They opine that, this is because the pressure for performance has been more external than a genuine internally driven desire. This observation prompted some scholars to call for a review of the performance management process (André, 2010).

In Kenya, the Balanced Score Card (BSC) was employed to measure performance of public sector institutions (Ministry of Devolution and Planning, 2013). This approach lays emphasis on 
financial and non-financial parameters. Kirkman, Lowe and Young (1999) have recommended this approach in performance measurement. The use of BSC in measurement of performance of public institutions is widely recognized even though adoption rate is low (Northcott \& Taulapapa, 2012). The methodology is one of the most comprehensive measures of corporate performance. The BSC approach was adopted in this study.

\section{RESEARCH METHODOLOGY}

\subsection{Research Design}

The study adopted a cross-sectional design. The approach was selected because it is simple, affordable and ensured completion of the study within the given time and resource constraints. The study was guided by the positivist philosophical paradigm which lays emphasis on verifiability of knowledge and truth (Philips \& Burbules, 2000). Positivists believe that reality is external and can be measured using standard scientific tools and methods. Additionally, causality can be studied and described using scientific methods (Copleston, 2003).

\subsection{Study Population}

The target population for this study was all State Corporations in Kenya. The accessible or survey populations were the 200 State Corporations that were evaluated during the Financial Year 2014/2015.

\subsection{Sampling Frame}

The sampling frame comprised the list of State Corporations that were evaluated during the Financial Year 2014/15 (Ministry of Devolution and Planning, 2014). This had a total of 200 State Corporations.

\subsection{Sample Size and Sampling Technique}

The study employed a scientific formula of calculate sample size (Mugenda and Mugenda, 2003). The calculated sample size was 132 State Corporations. Simple random sampling method was used in selection of State Corporations that participated in the study.

\subsection{Data Collection Instrument}

An open ended and closed questionnaire was used for data collection. Questionnaires are widely used in economic and business research (Kothari, 2011). The process of developing the questionnaires ensured that the basic principles were observed (Kothari, 2011).

\subsection{Pilot Study}

The study questionnaire was pre-tested before adoption using a group similar to the study population (Mugenda \& Mugenda, 2003). The questionnaire was pretested to assess understanding, time taken, reliability and validity of the instrument. A total of 12 State Corporations were involved in the pre-test which represented $8.96 \%$ of the sample size.

\subsection{Data Processing and Analysis}

After data collection, all questionnaires were assessed for missing data and assigned a number. Coding was undertaken to facilitate data entry using statistical package for social sciences
(SPSS). Data analysis was done using descriptive statistics and multiple regressions.

\section{RESULTS}

\section{1 Descriptive Statistics on Strategic Planning 4.1.1 Strategic Plan Development}

Out of the 132 respondents sampled 102 responded to the questionnaire. An overwhelming majority (97.1\%) of the respondents had valid strategic plans while a few $(2.9 \%)$ did not have. This finding clearly demonstrates that the government has laid a lot of emphasis on development of strategic plan for all State Corporations. The study also found out that all state corporations involve their workers in the development of strategic plans which could probably be explained by the fact that this process is a target area in performance contracting which commits all workers. Additionally, majority $(60.6 \%)$ of the respondents reported that board members are involved in strategic planning while other stakeholders and consultants took part in $30.3 \%$ and $28.3 \%$ corporations respectively. The fact that nearly a third of the respondents reported that their board members were not involved in strategic planning development is a pointer that state corporations need to invite all board members during this process so that they can embrace and own it.

\subsubsection{Strategic plan implementation}

There were various methods used to cascade strategic plan. Majority (57.6\%) of the respondents cascaded strategic plans through sensitization forums/meetings, 35.4\% used emails and memos while a few (27.3\%) distributed hard copies. Cascading of the strategic plan was also done orally by $44.4 \%$ of the respondents, $37.4 \%$ in writing while a few (19.1\%) used both means. The study also found out that $(74.7 \%)$ of the respondents reported that cascading was done in the first quarter, $14.1 \%$ did it during the second quarter while a few $(6 \%)$ cascaded the plan in the third and fourth quarter.

Regarding implementation, $41.4 \%$ of the respondents accomplished between $81 \%$ and $100 \%$ of the planned activities, $23.2 \%$ accomplished between $61 \%$ and $80 \%$ of the activities while $17.2 \%$ accomplished between $41 \%$ and $60 \%$ activities. This finding implies that majority of the planned activities in the strategic plans are achieved. Again, majority (99\%) of the respondents involved staff in the implementation of the strategic plan. $12.1 \%$ of the respondents involved board members while $9.1 \%$ of the respondents involved other stakeholders. Lastly, majority (98\%) of the respondents reported that strategic planning had a positive influence on corporate performance of state corporations in Kenya.

\subsection{Diagnostic test for study variables}

Violating statistical assumptions can invalidate statistical data results as majority of the statistical tests depend on various assumptions to draw conclusions about a sample (Pedace, 2013). When these assumptions are not met there may be either Type I or Type II error(s) which may invalidate the results of the analysis (Osborne \& Waters, 2002).

\subsubsection{Validity and Reliability of Data}


Cronbach's alpha was computed to determine reliability of the data. The predictor variable achieved an alpha value of 0.773 . The dependent variable achieved an alpha value of 0.9680 . This was considered an indicator for high reliability as it exceeds the 0.7 threshold (Fraenkel \& Wallen, 2006). In order to determine construct validity, confirmatory factor analysis (CFA) was done. Evidence of construct validity was demonstrated by presence of both discriminant and convergent validity. None alone is sufficient for measuring construct validity (Hair, Black \& Babin, 2010).

\subsubsection{Test for Suitability of Structure Detection}

For sampling adequacy of the study, Kaiser-Meyer-Olkin (KMO) and Bartlett's test of sphericity were conducted. The KMO value in the study was 0.575 which satisfied the minimum criteria suggested by Kaiser (1974). In addition, the prob. value of Bartlett's test of sphericity was 0.000 (which was less than 0.05) an indication that the correlation between the items at the 5 percent level of significance was sufficient and adequate for further analysis.

\subsubsection{Normality of Observations}

Normality of observations is used to visualize the distribution of data or observations. This makes it a major assumption in most statistical analysis. Aluja, Blancha and Garcia (2005) stated that normality is confirmed if none of the values for skewness and kurtosis exceed +1 or -1 . The predictor variable had a skewness of -0.609 and kurtosis 0.744 . The dependent variable had a skewness of -0.816 and kurtosis 0.333 . This implied that the assumption of normality was satisfied.

\subsubsection{Autocorrelation Among Variables}

Durbin Watson statistic test was computed in order to determine if the predictor variable was auto correlated with other predictor variables. Gujarati (2003) stated that coefficients ranging from 1.5 to 2.5 signify absence of autocorrelation. In this study the coefficient value was 2.094 indicating absence of autocorrelation amongst the study variables.

\subsection{Correlation Analysis Results}

Correlation results show that as strategic plan improves, there is a reduction in the performance composite score. Since a lower score is preferred, improvement in the predictor variable improves the dependent variable and vice versa. This is significant at $95 \%$ confidence level $(r=-0.448, p<0.05)$. Similarly, the constructs of the predictor variable have a similar relationship with the dependent variable. Strategic plan development has a correlation coefficient of $-0.304, p<0.05$ while strategic plan implementation has a coefficient of $-0.300, \mathrm{p}<0.05$.This means that strategic plan development and implementation reduces the performance contract composite score implying improved performance since lower scores are more preferred. These findings are supported by the current literature (Ogunmokun \& Tang, 2012; Poister, 2010; Kaissi \& Bengun, 2008)

\subsection{Regression analysis results}

The regression analysis is shown in Table 1 . The ability of strategic planning to explain the variance in performance of State Corporation is explained by the constant $(\beta 0=0.266, \mathrm{p}<0.05)$ and coefficient of strategic planning $(\beta 1=-0.380, \mathrm{p}<0.05)$.
Table 1: Regression of Strategic Planning on Performance

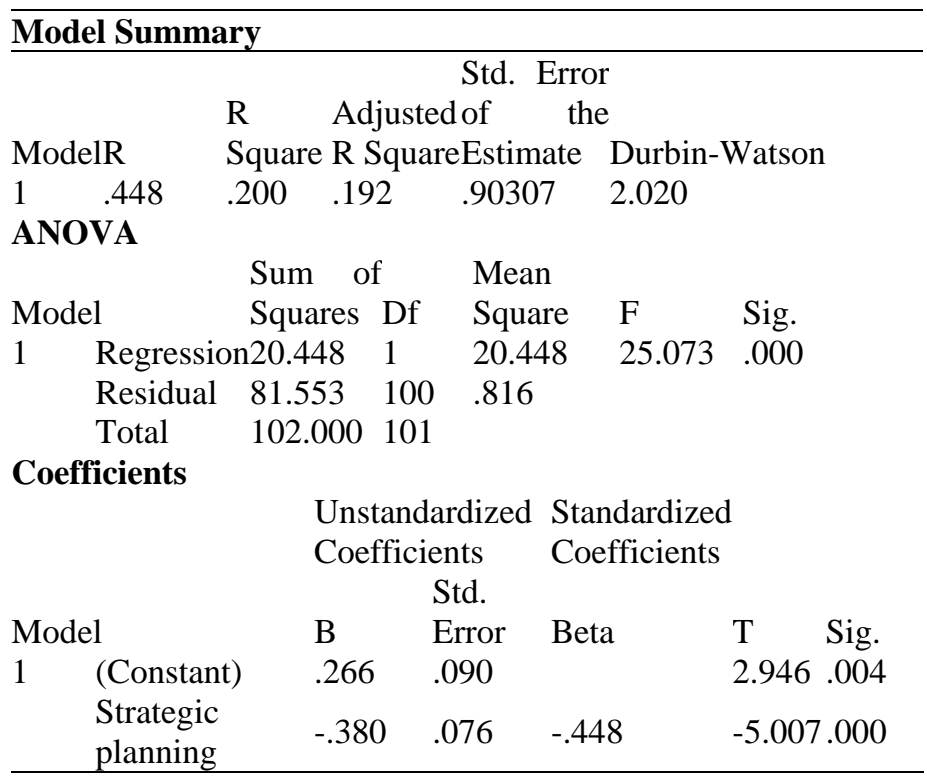

Note: $n=102, p<0.05$.

Thus, the causal influence for the two variables is depicted as $\mathrm{Y}=$ $\beta 0+\beta 1 \mathrm{X} 1+\varepsilon$. Where $\mathrm{Y}=$ Performance of State Corporation $\beta 0=$ Performance of State Corporation in absence of strategic planning

$\beta 1=$ Coefficient of strategic planning

$\mathrm{X} 1$ = Strategic planning

$\varepsilon=$ Error term

When the values in the model are fitted, it reflects as follows:

$\mathrm{Y}=0.266-0.380 \mathrm{X} 1+\varepsilon$

The models shows that improvements in strategic planning will lead to improvements in performance of State Corporation score as lower scores are preferred. The prediction power of this model is significant at $95 \%$ confidence level since both the constant and strategic planning have $\mathrm{p}<0.05$. This implies there is a statistically significant influence of strategic planning on performance of State Corporations in Kenya. The model summary shows that the predictor variable explains $20 \%$ of the variance in the independent variable namely performance of State Corporation. The model is a good fit and exists $(\mathrm{F}=25.073, \mathrm{p}<$ $0.05)$. When the construct for the predictor variable were regressed on the dependent variable the results shows that development of a strategic plan has a bigger influence on performance $(\beta=-0.203)$ compared with strategic plan implementation $(\beta=-0.193)$.

The results are similar to those of other scholars who have stated that strategic plan implementation enhances a firm's competitive advantage against competitors (Hill \& Jones, 2009; Olanipekun et al, 2015). The study's results are inconsistent with the findings of Song et al (2011). These scholars have stated that new product development requires one to think outside the box which is contrary to the principles of strategic planning. Their study covered 227 private firms and this may explain the differences in results with this study. Gathenya (2012) study findings also established a negative moderation effect of strategic management process on performance probably because the study 
targeted small and medium enterprises. These finding that strategic planning influences performance of State Corporations in Kenya concur with the resource based view. This theory states that corporate performance is influenced by resources available (Madhani, 2010). Strategic plan is one of the resources and therefore by extension this does influence corporate performance.

\section{CONCLUSIONS AND RECOMMENDATIONS}

The study has established that almost all State Corporations in Kenya have developed a strategic plan. Further, strategic planning influences performance of State Corporations in Kenya. Thus a positive change in the predictor variable positively influences the dependent variable and vice versa. The constructs of the predictor variable had similar influence on the dependent variable. Regarding the constructs for the predictor variable, the study has also established that a unit change in strategic plan developed has greater influence on the dependent variable compared with a unit change in strategic plan implementation. The study recommends that all State Corporations should have a valid strategic plan to guide operations. A broad range of stakeholders should be involved in its development with emphasis on participation of members of the board. Finally, strategic plans should be implemented in order to realize the full gains of strategic planning process.

\section{REFERENCES}

[1] Aluja, A., Blancha, A., \& García, L. F. (2005). Dimensionality of the maslach burnout inventory in school teachers. European Journal of Psychological Assessment. 21(1), 67-76.

[2] André, A. (2010). Achieving high performance in the public sector. Public Performance \& Management Review. 34(1), 81-103.

[3] Anjula, G. (2009). Adaptation of Indian public sector to market-based economic reforms: A resource-based perspective. International Journal of Public Sector Management. 22(6), 516-531.

[4] Berg A. V., Grift, Y., \& Witteloostuijn, A. (2011). Works Councils and organizational performance. The role of top managers' and Works Councils' attitudes in bad vis-à-vis good times. Journal of Labor Research. 32, 136156.

[5] Brown, E. (2007). Competitive advantage and the resource based view of the firm. Retrieved from http://ericbrown.com/competitive-advantage-and-theresource-based-view-of-the-firm.htm.

[6] Copleston, F. (2003). Logical positivism and existentialism. London, UK: MPG Limited.

[7] Fourie, D. (2014). The role of public sector enterprises in the South African economy. African Journal of Public Affairs. 7(1) 30-40

[8] Fraenkel, J. R., \& Wallen N. E. (2006). How to design and evaluate research in education. New York, USA: McGraw Hill.

[9] Frantz, M. (2013). Definition of strategic objectives. Retrieved from http://www.achieveit.com/definition-of-strategic-objectives/.

[10] Gathenya, J. W. (2012). Strategic planning practices and firm performance among women- led small and medium enterprises in Kenya. Unpublished Doctoral Thesis, Kenya: Jomo Kenyatta University of Agriculture and Technology.

[11] Gaya, H. \& Struwig, M. (2016). Is activity-resource-based view (ARBV) the new theory of the firm creating sources of sustainable competitive advantage in service firms? Global Journal of Management: Administration and Management 16(5).

[12] Gestel, K. V. (2012). How governance of complex ppps affects performance. PAQ Summer, $140-148$
[13] Gujarati, D. N. (2003). Basic econometrics. 4th (ed.) . New York, USA: McGraw-Hill.

[14] Hair, J. F., Black, W. C., \& Babin, B. J. (2010). Multivariate data analysis: A Global perspective. Upper Saddle River, NJ: Pearson Prentice-Hall.

[15] Hill, C.W., \& Jones, G.R. (2009). Essentials of strategic management. (2nd ed.). Ohio: South-Western.

[16] Hoopes, D. G., Madsen, T. 1., \& Walker, G. (2003). Why is there a resourcebased view? Towards a theory of competitive heterogeneity. Strategic Management Journal. 24, 889-901.

[17] Jurevicius, O. (2013). Strategic management \& strategic planning process. Retrieved from http://www.strategicmanagementinsight.com/topics/strategicplanningprocess.html.

[18] Jurevicius, O. (2013). Pest \& pestel analysis. Retrieved from http://www.strategicmanagementinsight.com/tools/pest-pestelanalysis.html.

[19] Kabue, L. W., \& Kilika, J. M. (2016). Firm resources, core competencie and sustainable competative advantage: An intergrative theoretical framework. Journal of Management and Strategy 7(1), 98-108.

[20] Kaissi, A. A., Bengun, J. W., \& Hamiliton, J. A. (2008). Strategic planning processes and hospital financial performance. Journal of Healthcare Management. 53(3), 97-209.

[21] Kanyane, H., \& Sausi, K. (2015). Reviewing state-owned entities' governance landscape in South Africa. African Journal of Business Ethics. 9(1), 28-41.

[22] Karen, F., Jiju, A., \& Susan, O. (2009). Performance management in the public sector. International Journal of Public Sector Management. 22(6), 478498.

[23] Kirkman, B. L., Lowe, K. B., \& Young, D. P. (1999). High-performance work organizations. Definitions, practice and an annotated bibliography. North Calorina: Greensboro.

[24] Kothari, C. (2011). Research methodology: Methods and techniques, 2nd Edition . New Delhi, India: New Age International Publishers.

[25] Madhani, P. (2010). Resource based view: Concepts and practices. Hyderabad, India: Icafai University Press.

[26] Michael, A. (2002). The decision and implementation of privitization in Tanzania. Unpublished Masters Thesis, Netherlands: Institute of Social Studies, Graduate School of Development Studies.

[27] Ministry of Devolution and Planning. (2013). Performance contracting guidelines (10th ed). Nairobi, Kenya: Ministry of Devolution and Planning.

[28] Ministry of Devolution and Planning. (2014). List of state corporations evaluated for FY 2013/ 2014. Nairobi, Kenya: Ministry of Devolution and Planning.

[29] Mugenda, O. M., \& Mugenda, A. G. (2003). Research method; Quantitative and qualitative approaches. Nairobi, Kenya: African Centre for Technology Studies.

[30] Newbert, S. (2007). Empirical research on the resource based view of the firm: An assesment and suggestions for future research. Strategic Management Jourmal, 28 121-146.

[31] Njiru, E. (2008, October). The role of state corporations in a developmental state: The Kenyan experience. 30th Aapam Annual Roundtable Conference, Accra, Ghana.

[32] Northcott, D., \& Taulapapa, T. M. (2012). Using the balanced scorecard to manage performance in public sector organizations issues and challenges. International Journal of Public Sector Management. 25(3), 166-191.

[33] Ochieng, E. O. (2010). Public sector reforms \& performance contracting case study Kenya Retrieved from: http://www.scribd.com/doc/42930427/Performance-Contracting-in-Kenya

[34] Ogunmokun, G. O., \& Tang, E. C. H. (2012). The effect of strategic marketing planning behaviour on the performance of small- to medium-sized firms. International Journal of Management. 29(1), 159-170.

[35] Olanipekun, W. D., Abioro, M. A., Akanni, L. F., Arulogun, O. O., \& Rabiu, R. O. (2015). Impact of strategic management on competitive advantage and organizational performance- Evidence from Nigeria bottling company. Journal of Policy and Development Studies. (9) 2, 185-198.

[36] Osborne, J. W., \& Waters, E. (2002). Four assumptions of multiple regression that researchers should always test. Practical Assessment, Research, and Evaluation, 8(2), 1-5. 
[37] Pedace, R. (2013). Multicollinearity: Econometrics for dummies. Hoboken, NJ: Willey.

[38] Philip, D. C., \& Burbules, N. C. (2000). Positivism and educational research. Oxford, England: Rowman \& Littlefield Publishers.

[39] Poister, H. (2010). The future of strategic planning in the public sector: Linking strategic management and performance. Public Administration Review, Special Issue, 70(1), 246-254.

[40] Priem, R. L., \& Butler, J. E. (2001). Is the resource-based" view" a useful perspective for strategic management research. Academy of Management Review. 26(1), 22-40.

[41] RoK. (1965). Sessional paper number 10 of 1965 on african socialism and its application to planning in Kenya. Nairobi, Kenya: Government Printers.

[42] RoK. (2012). State Corporation Act Chapter 446. Nairobi, Kenya: National Council for Law Reporting.

[43] RoK. (2013). Report of the presidential taskforce on parastatal reforms. Nairobi: Office of the President

[44] Simpson, S.N.Y. (2013). Public sector reform and disclosure practices of state-owned enterprises. The case of Ghana. Unpublished $\mathrm{PhD}$ Thesis, Britain: University of Birmingham.

[45] Song, M., Im, S., Bij,V. D., \& Song, L. Z. (2011). Does strategic planning enhance or impede innovation and firm performance? . Journal of Product Innovation Management. 28, 503-520.

[46] Theil, S.V., \& Leeuw, F. L. (2002). The performance paradox in the public sector. Public Performance \& Management Review. 25(3), 267-281.

[47] Wade, M., \&. Hulland, J. (2004). The resource based view and information systems research: Review, extension and suggestions for future research. MIS Quarterly, 107-142.
[48] Walker, T. (2008). Some alternative approaches to performance management for councils. International Journal of Productivity and Performance Management. 5(4), 339-344.

\section{AUTHORS}

First Author: John Muturi Mwangi (PhD). Manager, National Authority for the Campaign Against Alcohol and Drug Abuse (NACADA), Nairobi, Kenya. Tel + 254712116485. Email Address: muturij2002@yahoo.com

Second Author: Morris Irungu Kariuki (PhD). Lecturer, University of Nairobi, Nairobi, Kenya. Tel+254722496174. Email Address: mikariuki2003@gmail.com

Third Author: Peter Githae Muturi (PhD). Jomo Kenyatta University of Agriculture and Technology, Nairobi, Kenya. Tel+254722855473...Email Address: githaepm@yahoo.com

Correspondence Author: John Muturi Mwangi (PhD). Manager, National Authority for the Campaign Against Alcohol and Drug Abuse (NACADA), Nairobi, Kenya. Tel + 254712116485. Email Address: muturij2002@yahoo.com 